\title{
Near-Infrared Spectroscopy Measurement of Oxygen Extraction Fraction and Cerebral Metabolic Rate of Oxygen in Newborn Piglets
}

\author{
DEREK W. BROWN, JENNIFER HADWAY, AND TING-YIM LEE \\ Imaging Division [D.W.B., J.H., T.-Y.L.], Lawson Health Research Institute, London, Ontario, Canada, \\ N6A 4V2; Imaging Research Laboratories [D.W.B., T.-Y.L.], Robarts Research Institute, London, Ontario, \\ Canada, N6A 5K8; and Department of Medical Biophysics [D.W.B., T.-Y.L.], University of Western
}

Ontario, London, Ontario, Canada, N6A $5 \mathrm{~K} 8$

\begin{tabular}{|c|c|}
\hline \multicolumn{2}{|c|}{ ABSTRACT } \\
\hline 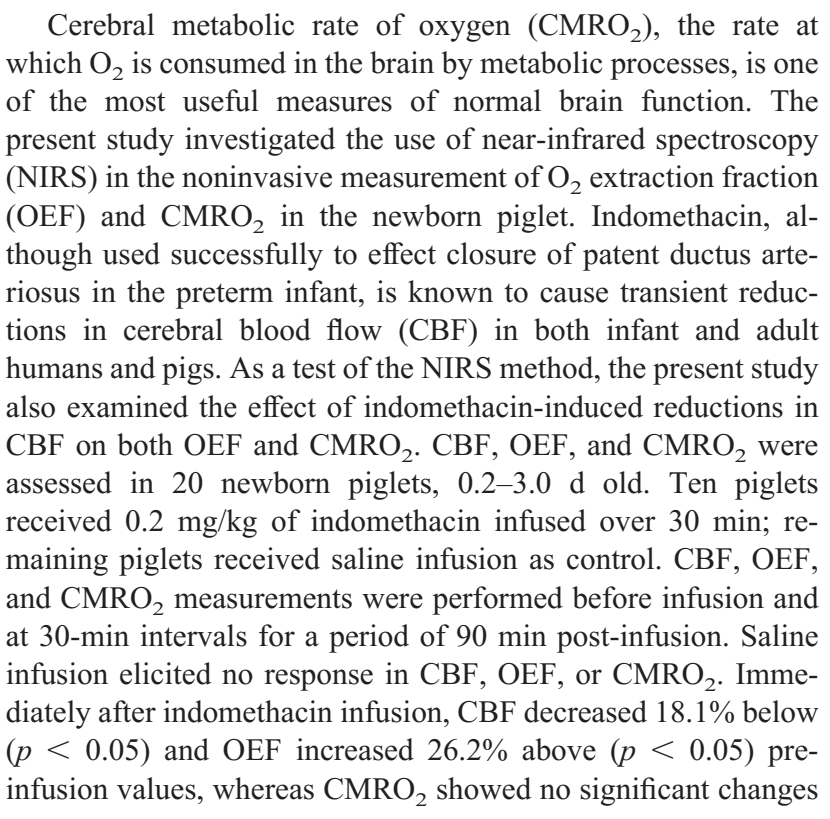 & 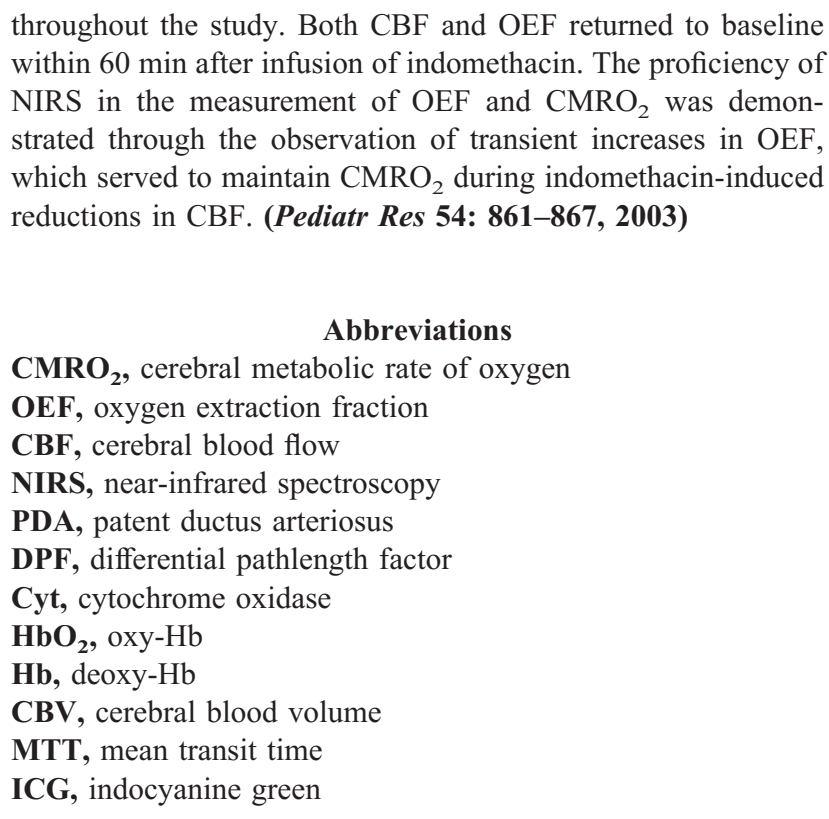 \\
\hline
\end{tabular}

Cerebral metabolic rate of oxygen $\left(\mathrm{CMRO}_{2}\right)$, the rate at which $\mathrm{O}_{2}$ is consumed in the brain by metabolic processes, is a key indicator of normal brain function. A means of accurately, noninvasively measuring $\mathrm{CMRO}_{2}$ at the bedside would provide vital information in the clinical assessment of preterm infants. However, difficulties associated with bedside measurement of cerebral blood flow $(\mathrm{CBF})$ and $\mathrm{O}_{2}$ extraction fraction (OEF) in the brain have prevented the development of clinically viable $\mathrm{CMRO}_{2}$ measurement techniques and the widespread clinical use of $\mathrm{CMRO}_{2}$ as an indicator of proper brain

Received February 13, 2003; accepted July 7, 2003.

Correspondence: Ting-Yim Lee, Ph.D., Imaging Division, Robarts Research Institute, 100 Perth Drive, London, Ontario N6A 5K8, Canada; email: tlee@imaging.robarts.ca

DOI: 10.1203/01.PDR.0000090928.93045.BE function. The near-infrared spectroscopy (NIRS) system used in the present study allows for quantitative measurement of both $\mathrm{CBF}$ and OEF at the bedside and thus may provide a clinically useful means of measuring $\mathrm{CMRO}_{2}$ in the newborn human infant.

As a test of the NIRS method, the present study investigated the effect of the nonsteroidal anti-inflammatory drug indomethacin on both $\mathrm{OEF}$ and $\mathrm{CMRO}_{2}$ in the anesthetized newborn piglet. Indomethacin is currently used in the treatment of patent ductus arteriosus (PDA), a common condition among preterm infants that has been shown to increase the risk of intraventricular hemorrhage, bronchopulmonary dysplasia, and death in this group (1). Although useful in the treatment of PDA, administration of indomethacin is known to cause a transient reduction in CBF in both human and animal newborns (2-4). 
Because reductions in $\mathrm{CBF}$ compromise $\mathrm{O}_{2}$ delivery, concern has been raised as to whether indomethacin administration may also alter $\mathrm{CMRO}_{2}$. Several studies previously reported in the literature have investigated the effect of indomethacin on $\mathrm{CMRO}_{2}$ in newborn human and animal models with varying results $(2,5-7)$, likely attributable to different indomethacin doses used and to differences in techniques used for $\mathrm{CMRO}_{2}$ measurement. Benders et al. (5), inferring $\mathrm{CMRO}_{2}$ from cytochrome oxidase (Cyt) measurement, and Pourcyrous et al. (2), using microsphere-measured $\mathrm{CBF}$ and venous (sagittal sinus) blood samples to calculate $\mathrm{CMRO}_{2}$, both observed a decrease in $\mathrm{CMRO}_{2}$ after indomethacin infusion in preterm infants (indomethacin dose of $1 \mathrm{mg} / \mathrm{kg}$ ) and newborn piglets (3-5 d old; indomethacin dose of $5 \mathrm{mg} / \mathrm{kg}$ ), respectively, whereas van Bel et al. (6) found indomethacin administration (1 mg/kg) had no effect on $\mathrm{CMRO}_{2}$ in the fetal lamb. Coyle et al. (7) found that high-dose $(5 \mathrm{mg} / \mathrm{kg})$ indomethacin elicited a decrease in $\mathrm{CMRO}_{2}$, whereas lower-dose $(3 \mathrm{mg} / \mathrm{kg})$ indomethacin treatment had no effect in newborn piglets 3-5 d old, reporting that increases in OEF during indomethacin-induced reductions in $\mathrm{CBF}$ were sufficient to maintain $\mathrm{CMRO}_{2}$ in the lower dose group. In the present study, we sought to demonstrate the ability of NIRS to measure noninvasively both OEF and $\mathrm{CMRO}_{2}$ in the newborn piglet using, as a test of the NIRS measurements, transient increases in OEF that serve to maintain $\mathrm{CMRO}_{2}$ during indomethacin-induced reductions in $\mathrm{CBF}$.

\section{METHODS}

Theory. NIRS has been used in a variety of studies to investigate cerebral hemodynamics since the first publication by Jobsis in 1977 (8-10). The underlying principles behind the use of NIRS to probe biologic media are relatively simple and have been described in detail elsewhere $(8,11-15)$. There exist in biologic tissue four endogenous NIR light absorbers, oxy-Hb $\left(\mathrm{HbO}_{2}\right)$, deoxy-Hb $(\mathrm{Hb})$, Cyt, and water. Because $\mathrm{HbO}_{2}$ and $\mathrm{Hb}$ are generally present at relatively low concentrations in tissue, NIR light is able to penetrate tissue to a greater extent than other frequencies of light, in some cases up to distances of 8-9 $\mathrm{cm}(13)$.

As NIR light enters tissue, it is multiply scattered. This scatter increases the total pathlength traveled by NIR light such that the actual pathlength is greater than the physical distance between the points of emission and detection. The increase in distance can be accounted for using the differential pathlength factor (DPF) first described by Delpy et al. (16). With accurate knowledge of the DPF, a modified version of the Beer-Lambert law can be used to determine absolute changes in concentrations of NIR absorbers within tissue:

$$
\Delta \mathrm{c}=\frac{\Delta \mathrm{A}}{\alpha \cdot \mathrm{L} \cdot \mathrm{B}}
$$

where $\Delta \mathrm{c}$ is the change in concentration, $\Delta \mathrm{A}$ is the change in attenuation, $\alpha$ is the extinction coefficient, $\mathrm{L}$ is the physical distance between emission and detection of NIR light, and B is the DPF. We used a cooled CCD spectrometer to acquire high signal-to-noise NIR spectra from 600 to $980 \mathrm{~nm}$ with a spectral sampling width of $0.395 \pm 0.001 \mathrm{~nm}$. The acquired spectra enable the DPF to be estimated using the second derivative technique, as described by Matcher et al. (17).

For a complete discussion of the use of NIRS to measure $\mathrm{CBF}$, cerebral blood volume $(\mathrm{CBV})$, and mean transit time (MTT), see Brown et al. (18). Briefly, the technique requires i.v. administration of the NIR chromophore indocyanine green (ICG). CBF, CBV, and MTT calculations are based on deconvolution as discussed below. If we consider a network of capillaries in a certain mass of brain tissue, then CBF into the network is $\mathrm{F}\left(\mathrm{mL} \cdot \mathrm{min}^{-1} \cdot 100 \mathrm{~g}^{-1}\right)$ and is carrying with it ICG at concentration of $\mathrm{C}_{\mathrm{a}}(\mathrm{t})(\mu \mathrm{mol} / \mathrm{mL})$. The tissue concentration function, or the tissue residue function, $\mathrm{Q}(\mathrm{t})(\mu \mathrm{mol} / \mathrm{mL})$, can be measured using NIRS. In the special case when $\mathrm{F} \cdot \mathrm{C}_{\mathrm{a}}$ is a delta function such that a unit mass of ICG is deposited in the tissue instantaneously at time 0 , the tissue residue function becomes the impulse residue function (IRF) or R(t) (19). The length of the initial plateau of the IRF at unity height corresponds to the minimum time required for the blood to traverse the network from the arterial inlet to the venous outlet, or the minimum transit time.

When ICG is injected i.v. at a peripheral vein, the rate of delivery of the tracer to the capillary network is $\mathrm{F} \cdot \mathrm{C}_{\mathrm{a}}(\mathrm{t})$. If the mass of ICG in the network is linear with respect to the arterial (input) concentration and $\mathrm{F}$ is constant in time, then by linear superimposition, it can be shown that

$$
\mathrm{Q}(\mathrm{t})=\mathrm{F} \cdot \mathrm{C}_{\mathrm{a}}(\mathrm{t}) * \mathrm{R}(\mathrm{t})
$$

where * is the convolution operator. $\mathrm{Q}(\mathrm{t})$ and $\mathrm{C}_{\mathrm{a}}(\mathrm{t})$ can be measured by NIRS, and deconvolution between the two curves then yields $\mathrm{F} \cdot \mathrm{R}(\mathrm{t})(20)$, the initial height of which corresponds to $\mathrm{CBF}$ and the area under the curve to CBV (21). From the Central Volume Principle (22), MTT can then be calculated as follows:

$$
\mathrm{MTT}=\frac{\mathrm{CBV}}{\mathrm{CBF}}
$$

Arterial oxygen saturation $\left(\mathrm{SaO}_{2}\right)$ was calculated from partial arterial oxygen tension $\left(\mathrm{PaO}_{2}\right)$, measured from arterial blood samples, using the method described by Kelman et al. (23).

Arterial oxygen content was calculated using $\mathrm{SaO}_{2}$ as follows:

$$
\begin{aligned}
& \mathrm{CaO}_{2}=\left(\mathrm{Hb} \text { content in } \mathrm{g} / \mathrm{dl} * 1.39 \mathrm{ml} \mathrm{O}_{2} / \mathrm{g} \mathrm{Hb}^{2} \mathrm{SaO}_{2}\right) \\
&+\left(0.003 \mathrm{ml} \mathrm{O}_{2} / \mathrm{mmHg}^{2} * \mathrm{PaO}_{2}\right)
\end{aligned}
$$

where $\mathrm{CaO}_{2}$ is arterial oxygen content and $\mathrm{SaO}_{2}$ and $\mathrm{PaO}_{2}$ are arterial oxygen saturation and oxygen tension, respectively. The first part of the equation describes the amount of oxygen bound to $\mathrm{Hb}$; the second part describes the amount of oxygen dissolved in plasma. Our calculations showed the amount of oxygen dissolved in plasma to be negligible, and we therefore omitted it from $\mathrm{CaO}_{2}$ calculations.

Although the NIRS system described has the capability to accurately measure absolute $\mathrm{Hb}$ concentration in a given volume of tissue, it is unable to provide reliable measures of absolute $\mathrm{HbO}_{2}$ concentration. However, it is possible to use only absolute $\mathrm{Hb}$ concentrations to determine arteriovenous $\mathrm{O}_{2}$ 
difference when both $\mathrm{CBV}$ and the distribution of $\mathrm{CBV}$ into arterial, capillary, and venous compartments are known. Firstly, CBV expressed in milliliters per unit volume of brain tissue (equal to CBV expressed in milliliters per unit mass of brain tissue multiplied by the density of brain tissue, 1.05 $\mathrm{g} / \mathrm{mL}$ ) can be viewed as the dilution factor of the NIRS measurements, relative to blood sampling measurements. Thus, NIRS measurements can be converted into equivalent blood sampling unit by division with the factor $\mathrm{CBV} * \rho$, where $\rho$ is the density of brain tissue. Second, NIRS measurements do not distinguish between the arterial, capillary, and venous compartments of the cerebral circulation and thus reflect a weighted average of $\mathrm{Hb}$ concentrations within these different blood compartments in the region sampled. The relative distribution of arterial, capillary, and venous compartments in the CBV is generally accepted to be approximately $20 \%, 10 \%$, and $70 \%$ respectively (24). Using this distribution, $[\mathrm{Hb}]$ in the venous compartment can be isolated as follows:

$$
[\mathrm{Hb}]_{\mathrm{T}}=0.2[\mathrm{Hb}]_{\mathrm{a}}+0.1[\mathrm{Hb}]_{\mathrm{c}}+0.7[\mathrm{Hb}]_{\mathrm{v}}
$$

where $[\mathrm{Hb}]_{\mathrm{T}},[\mathrm{Hb}]_{\mathrm{a}},[\mathrm{Hb}]_{\mathrm{c}}$, and $[\mathrm{Hb}]_{\mathrm{V}}$ are the concentrations of total $\mathrm{Hb}$, arterial $\mathrm{Hb}$, capillary $\mathrm{Hb}$, and venous $\mathrm{Hb}$, respectively. Using the assumption that capillary concentration of $\mathrm{Hb}$ is the mean of arterial and venous concentrations, it is then possible to solve for $[\mathrm{Hb}]_{\mathrm{v}}$ given that $[\mathrm{Hb}]_{\mathrm{T}}$ can be measured with NIRS and $[\mathrm{Hb}]_{\mathrm{a}}$ can be calculated from $\mathrm{SaO}_{2}$ using measured $\mathrm{Hb}$ content of arterial blood and $\mathrm{CBV}$ as a measure of the percentage of blood in a given tissue volume. Because $\mathrm{Hb}$ is generated in the brain solely through the process of $\mathrm{O}_{2}$ dissociation from $\mathrm{HbO}_{2}$, the difference in $[\mathrm{Hb}]_{\mathrm{a}}$ and $[\mathrm{Hb}]_{\mathrm{v}}$ is identical, although opposite in sign, to the difference in $\left[\mathrm{HbO}_{2}\right]_{\mathrm{a}}$ and $\left[\mathrm{HbO}_{2}\right]_{\mathrm{v}}$, assuming that $\mathrm{CBV}$ remains constant during the 40 -s measurement period. The arterio-venous $\mathrm{O}_{2}$ difference thus can be calculated as follows:

$$
\text { arterio-venous } \mathrm{O}_{2} \operatorname{diff}=\left([\mathrm{Hb}]_{\mathrm{v}}-[\mathrm{Hb}]_{\mathrm{a}}\right) * 1.39 \mathrm{ml} \mathrm{O}_{2} / \mathrm{gHb}
$$

where 1.39 is a factor that describes the amount of $\mathrm{O}_{2}$ bound per gram of $\mathrm{Hb} . \mathrm{CMRO}_{2}$ can then be calculated as follows:

$$
\mathrm{CMRO}_{2}=\mathrm{CBF} *\left(\text { arterio }- \text { venous } \mathrm{O}_{2} \text { diff }\right)
$$

$\mathrm{OEF}$, the percentage of oxygen extracted from arterial blood in the brain, was calculated using the method described by Mintun et al. $(25,26)$

$$
\mathrm{OEF}=\frac{\left(\text { arterio }- \text { venous } \mathrm{O}_{2} \text { diff }\right)}{\mathrm{CaO}_{2}}
$$

Subjects and studies. Twenty newborn piglets were studied. The study was approved by the Council on Animal Care, Animal Use Sub-Committee at the University of Western Ontario. Piglets were anesthetized using $1 \%$ isoflurane, paralyzed with vecuronium, intubated, and ventilated. Physiologic parameters, including $\mathrm{pH}$, partial arterial $\mathrm{CO}_{2}$ tension $\left(\mathrm{PaCO}_{2}\right)$, partial arterial $\mathrm{O}_{2}$ tension $\left(\mathrm{PaO}_{2}\right)$, heart rate, mean arterial blood pressure, and temperature, were monitored throughout the experiment. Table 1 presents the number of cerebral hemodynamic measurements made and the age and weight of individual piglets.

Ten piglets (mean age $24 \mathrm{~h}$ [range 2-60 h]; median weight $1.64 \mathrm{~kg}$ [range 1.3-2.4 kg]) received indomethacin infusion $(0.2 \mathrm{mg} / \mathrm{kg}$ infused over $30 \mathrm{~min})$; remaining piglets (mean age $19.5 \mathrm{~h}$ [range $2.5-53 \mathrm{~h}$ ]; median weight $1.53 \mathrm{~kg}$ [range 1.4-1.8 $\mathrm{kg}]$ ) received an equivalent volume of vehicle (saline), infused over $30 \mathrm{~min}$, as control. Indomethacin dose and administration regimens were chosen to match those used in the clinical treatment of PDA. NIRS CBF, CBV, and MTT measurements were performed before infusion (either $30 \mathrm{~min}$ or $5 \mathrm{~min}$ before the start of infusion), directly after infusion, and at 30-min intervals for $1.5 \mathrm{~h}$ thereafter. Two baseline measurements were performed on 15 piglets (eight in control group and seven in indomethacin group); a single baseline measurement was performed on the remaining five piglets. The number of postindomethacin measurements performed ranged from six to eight. For the presentation of results, the end of the infusion period is assigned a time of 0 min such that the start of infusion is at $-30 \mathrm{~min}$ and the baseline measurements are at -60 and/or $-35 \mathrm{~min}$.

NIRS tissue ICG concentration measurement. The NIRS system is composed of a tungsten halogen light source, two fiber optic cables, and a spectrometer. The spectrometer consists of a holographic grating housed in a custom-designed, light-tight container and a cooled CCD camera (Wright Instruments, Enfield, Middlesex, England). For the NIRS measurements, two fiber optic optodes were placed $3.0 \mathrm{~cm}$ apart on the head of the piglet. One of the optodes was used to transmit and the other to collect NIR light in the range $600-980 \mathrm{~nm}$. Multiply scattered light collected by the receive optode from the head of the piglet was relayed to the holographic grating, where it was dispersed across the cooled CCD chip (cooled to $-70^{\circ} \mathrm{C}$ to reduce electronic dark noise). The piglets received a $1.0-\mathrm{mL}$ injection of ICG solution at a concentration of 0.1 $\mathrm{mg} / \mathrm{mL}$ into the ear vein. As discussed in the above theory, a modified version of the Beer-Lambert law, which uses the DPF

Table 1. Age, weight, and number of cerebral hemodynamic measurements made for individual piglets

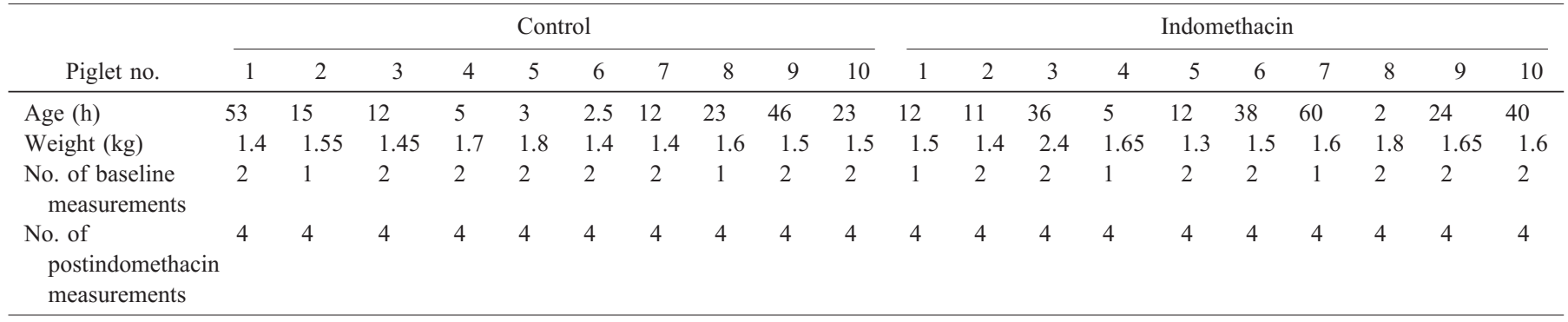


to account for the scatter, was used to calculate absolute change in ICG concentration within the illuminated tissue region with a temporal resolution of $200 \mathrm{~ms}$. Because the concentration of ICG in tissue is zero before injection, the absolute change in ICG is therefore the absolute concentration of ICG in tissue (18). Calculated values of CBF, CBV, and MTT are averages over the entire tissue region illuminated by the detected NIR light.

NIRS tissue absolute Hb concentration measurement. Using the techniques developed by Matcher (17), discussed in "Theory" above, absolute $\mathrm{Hb}$ concentrations within the illuminated tissue region were determined from spectra acquired immediately before ICG administration. The reported absolute $\mathrm{Hb}$ concentrations were obtained by averaging $\mathrm{Hb}$ concentrations determined from individual spectrum over a 3-s period before ICG administration. All spectra were acquired with a temporal resolution of $200 \mathrm{~ms}$.

Arterial ICG concentration measurement. Arterial ICG concentration was measured noninvasively on a hindfoot of the piglet using a Nihon Kohden dye densitogram unit (model DDG-2001 A/K, Tokyo, Japan). The dye densitogram probe was held on the skin of the piglet using a spring-loaded clip, much the same as is used for a regular pulse oximeter probe. The dye densitogram unit measured absolute ICG concentration in the arteries of the piglet, making one measurement every heartbeat. The normal piglet heart rate is between 110 and 130 beats/min, giving approximately one measurement every half-second (18).

Statistical analysis and data presentation. Post-infusion $\mathrm{CBF}, \mathrm{CBV}, \mathrm{MTT}, \mathrm{CMRO}_{2}$, and $\mathrm{OEF}$ measurements were compared with baseline measurements using two-way ANOVA with Tukey's test (27). For piglets in which two baseline measurements were performed, baseline values were averaged before inclusion in Figures 2 and 3. In Figures 3 and 4 , stars denote time points at which the mean $\mathrm{CBF}, \mathrm{CBV}$, MTT, $\mathrm{CMRO}_{2}$, or OEF value is significantly different from the corresponding baseline measurement $(p<0.05)$.

\section{RESULTS}

Figure 1 presents means and SDs of measured physiologic parameters in control (Fig. $1 A$ ) and treatment (Fig. 1B) piglets. No significant changes from baseline were observed in any physiologic parameter throughout the study.

Figure 2 shows typical attenuation spectra acquired during ICG administration. Spectra were acquired immediately before ICG administration (a), during the arrival of ICG in brain tissue (b), and at peak ICG concentration (c). ICG exhibits a strong, broad absorption band centered at $805 \mathrm{~nm}$ (28). Its presence and accumulation in the brain after bolus administration elicit increases in attenuation at approximately $805 \mathrm{~nm}$, as observed in Figure 2.

Figure 3 presents average NIRS-measured CBF, CBV, and MTT for control and indomethacin-treated piglets, respectively, at baseline, immediately after administration of indomethacin/saline, and at 30-min intervals after administration of indomethacin/saline for a period of $90 \mathrm{~min}$. No significant changes from baseline in any of $\mathrm{CBF}, \mathrm{CBV}$, or MTT were observed in control piglets throughout the study. In piglets
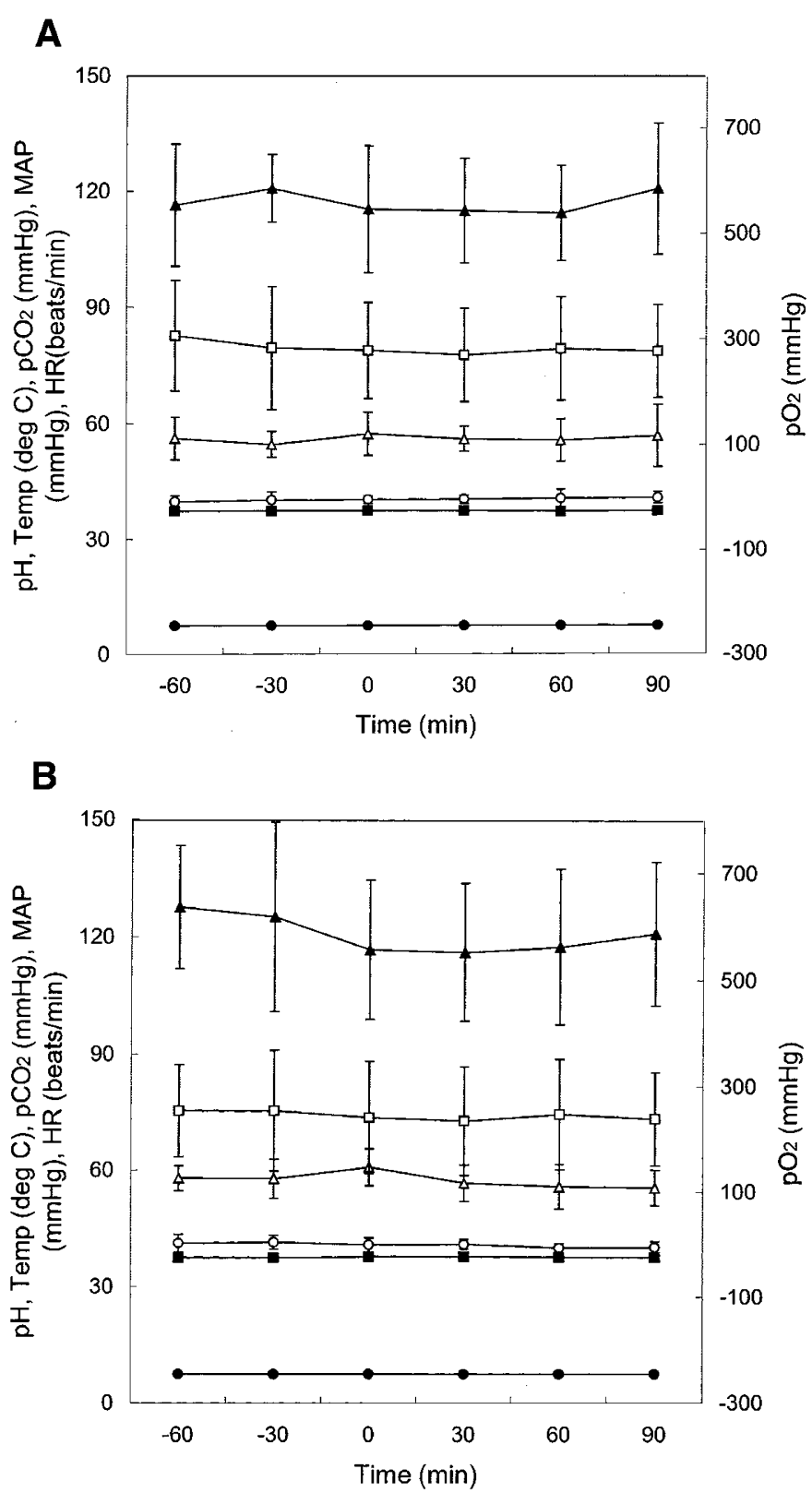

Figure 1. Physiologic parameters. Average physiologic parameters throughout entire study for control $(A)$ and indomethacin-treated $(B)$ piglets. $\bullet, \mathrm{pH} ; \bigcirc$, $\mathrm{PaCO}_{2} ; \mathbf{\square}$, temperature; $\square$, $\mathrm{PaO}_{2} ; \boldsymbol{\Lambda}$, heart rate; $\triangle$, mean arterial pressure.

treated with indomethacin, $\mathrm{CBF}$ decreased immediately after indomethacin infusion by an average of $8.0 \mathrm{~mL} \cdot \mathrm{min}^{-1} \cdot 100$ $\mathrm{g}^{-1}(18.1 \%)$ below baseline $(p<0.05)$. CBF subsequently returned to baseline within $60 \mathrm{~min}$ after indomethacin infusion. No significant changes in CBV from baseline were observed in piglets treated with indomethacin. MTT increased on average $1.2 \mathrm{~s}(29.8 \%)$ above baseline immediately after indomethacin infusion $(p<0.05)$ and remained slightly elevated for the remainder of the study.

Figure 4 presents average $\mathrm{CMRO}_{2}$ and $\mathrm{OEF}$ for control and indomethacin-treated piglets, respectively, at baseline, immediately after administration of indomethacin/saline, and at 30-min intervals after administration of indomethacin/saline for a period of 90 min. No significant changes in $\mathrm{CMRO}_{2}$ or $\mathrm{OEF}$ from 


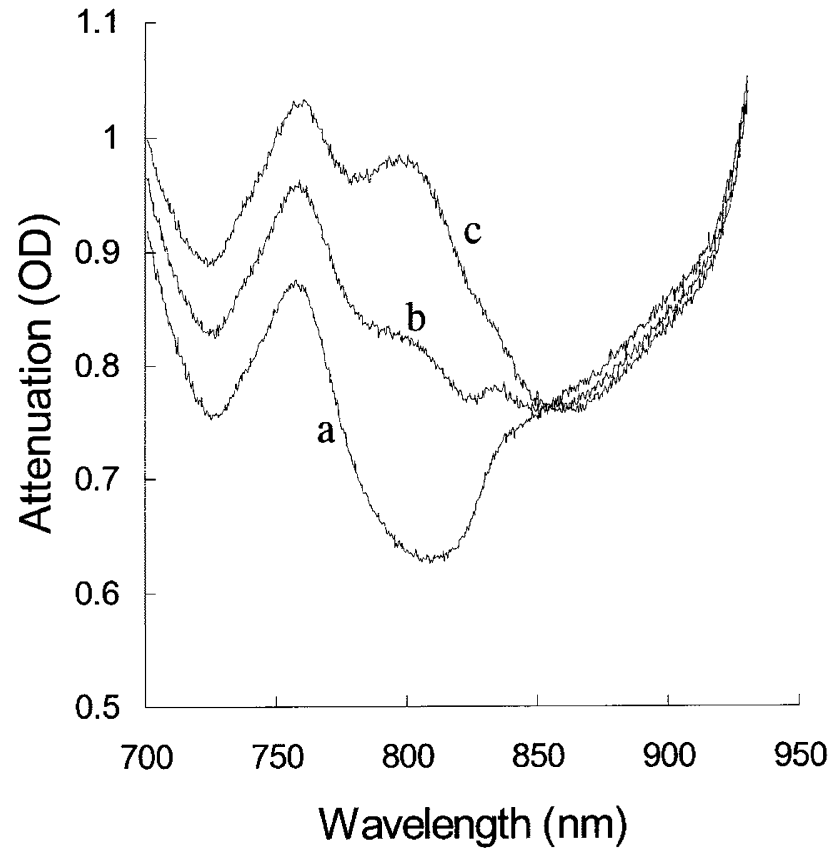

Figure 2. Representative attenuation spectra during ICG administration. Typical attenuation spectra acquired during ICG administration. Spectra were acquired before indomethacin administration (a), during the arrival of ICG in brain tissue (b), and at peak ICG concentration (c). ICG exhibits a strong absorption band centered at approximately $805 \mathrm{~nm}$. The observed increases in attenuation at approximately $805 \mathrm{~nm}$ in the presented spectra were the result of absorption by ICG.

baseline were observed in control piglets throughout the study. In piglets treated with indomethacin, no significant changes in $\mathrm{CMRO}_{2}$ from baseline were observed. However, OEF was significantly increased above baseline immediately after indomethacin infusion (average increase of $0.095[17.3 \%] ; p<0.05$ ) and returned to baseline within $60 \mathrm{~min}$ after infusion.

\section{DISCUSSION}

The results presented in the current study suggest a compensatory increase of OEF to maintain normal $\mathrm{CMRO}_{2}$ during reductions in $\mathrm{CBF}$ induced by indomethacin. $\mathrm{CMRO}_{2}$ values reported in the current study are in agreement with those observed in previous newborn piglet studies $(2,29-31)$. Springett et al. (29) used NIRS measured CBF with arterial and venous (sagittal sinus) blood samples to measure $\mathrm{CMRO}_{2}$ in anesthetized piglets $<24 \mathrm{~h}$ of age. They found an average baseline $\mathrm{CMRO}_{2}$ of $113 \mu \mathrm{mol} \cdot 100 \mathrm{~g}^{-1} \cdot \mathrm{min}^{-1}$ (or $2.53 \mathrm{~mL}$ $\mathrm{O}_{2} \cdot \min ^{-1} \cdot 100 \mathrm{~g}^{-1}$ ). The measured average baseline $\mathrm{CMRO}_{2}$ in the present study was $2.45 \mathrm{~mL} \mathrm{O}{ }_{2} \cdot \min ^{-1} \cdot 100 \mathrm{~g}^{-1}$. Pourcyrous et al. (2) found an average baseline $\mathrm{CMRO}_{2}$ of $3.57 \mathrm{~mL} \mathrm{O}_{2} \cdot \min ^{-1} \cdot 100 \mathrm{~g}^{-1}$ in awake 3- to 5-d-old piglets using microsphere $\mathrm{CBF}$ determination and venous (sagittal sinus) blood samples. Although this value is higher than our reported baseline value, it is to be expected that awake piglets should have a higher $\mathrm{CMRO}_{2}$ than those receiving anesthetics. Using microsphere-measured $\mathrm{CBF}$ and with arterial and venous (sagittal sinus) blood sampling, Ichord et al. (30) measured an average baseline $\mathrm{CMRO}_{2}$ of approximately $2.5 \mathrm{~mL}$ $\mathrm{O}_{2} \cdot \min ^{-1} \cdot 100 \mathrm{~g}^{-1}$ in 1 - to 2 -wk-old anesthetized piglets, in close agreement with our measurements. Bauer et al. (31) reported baseline $\mathrm{CMRO}_{2}$ values of $167 \mu \mathrm{mol} \cdot \mathrm{min}^{-1} \cdot 100$ $\mathrm{g}^{-1}$ (or $3.74 \mathrm{~mL} \mathrm{O} \mathrm{O}_{2} \cdot \mathrm{min}^{-1} \cdot 100 \mathrm{~g}^{-1}$ ) measured with microspheres and venous (sagittal sinus) blood samples in 2- to 5-d-old anesthetized piglets. Differences in $\mathrm{CMRO}_{2}$ values reported in the last study and those reported in the current study are likely due to differences in breed (mixed German domestic breed) and anesthetics used (nitrous oxide with isoflurane).

The ability to maintain $\mathrm{CMRO}_{2}$ through increases in OEF is possible only when sufficient $\mathrm{O}_{2}$ delivery is available. Piglets in the current study displayed comparatively high $\mathrm{PaO}_{2}$ values with respect to those previously reported in the literature (29, 30). Elevated $\mathrm{PaO}_{2}$ values are indicative of elevated arterial $\mathrm{O}_{2}$ content. Under conditions of decreased $\mathrm{O}_{2}$ delivery, elevated arterial $\mathrm{O}_{2}$ content provides an $\mathrm{O}_{2}$ reserve for cerebral metabolism. It is likely through use of this $\mathrm{O}_{2}$ reserve as well as through increases in OEF that the piglets studied were able to maintain constant $\mathrm{CMRO}_{2}$ during indomethacin-induced reductions in $\mathrm{CBF}$. The maintenance of $\mathrm{CMRO}_{2}$ through increases in OEF during indomethacin-induced reductions in CBF may merit further consideration with respect to the clinical use of indomethacin. Increases in OEF suggest that the cerebral circulation may be entering an "unstable" phase, in which any further reductions in $\mathrm{CBF}$ or perfusion pressure may trigger a drop in $\mathrm{CMRO}_{2}$ and ischemic damage, an important concern regarding the clinical use of indomethacin.

Whereas Benders et al. (5) and Pourcyrous et al. (2) both observed a decrease in $\mathrm{CMRO}_{2}$ with indomethacin administration in preterm infants and newborn piglets $(3-5 \mathrm{~d}$ old), respectively, our $\mathrm{CMRO}_{2}$ measurements showed no effect with indomethacin administration. There are several reasons for this ambiguity. Benders et al. (5) used NIRS-measured concentration of Cyt during changes in CBV to infer $\mathrm{CMRO}_{2}$. The NIRS technique used, however, did not allow for determination of the DPF, discussed in "Theory" above, and therefore required the assumption of a constant pathlength. In the event that CBV remains constant, this assumption is relatively accurate, but under conditions of changing $\mathrm{CBV}$, as reported in the same study, this assumption becomes invalid, preventing accurate determination of changes in chromophore concentration. Pourcyrous et al. (2) used higher doses of indomethacin (5 $\mathrm{mg} / \mathrm{kg}$ ) than the present study to elicit a drop in $\mathrm{CMRO}_{2}$, an observation also reported by Coyle et al. (7) in newborn piglets receiving similar indomethacin dose. However, in the same study, Coyle et al. (7) observed that lower dose indomethacin treatment $(3 \mathrm{mg} / \mathrm{kg})$ had no effect on $\mathrm{CMRO}_{2}$ with concomitant trends of decreases in CBF and increases in OEF. Our results in newborn piglets receiving $0.2 \mathrm{mg} / \mathrm{kg}$ of indomethacin are consistent with those reported by Coyle et al. (7). In a study investigating the cerebral hemodynamic and metabolic effects of indomethacin $(20 \mathrm{mg} / \mathrm{kg})$ in adult male baboons, Schumann et al. (32) used positron emission tomography to measure $\mathrm{CMRO}_{2}$ and reported a decrease in CBF with concomitant increases in OEF and no significant changes in $\mathrm{CMRO}_{2}$ with indomethacin infusion in brain regions matching those investigated in the current study. Although the absolute values of $\mathrm{CBF}, \mathrm{OEF}$, and $\mathrm{CMRO}_{2}$ cannot be compared directly because age and species differences, the general trends of measured 

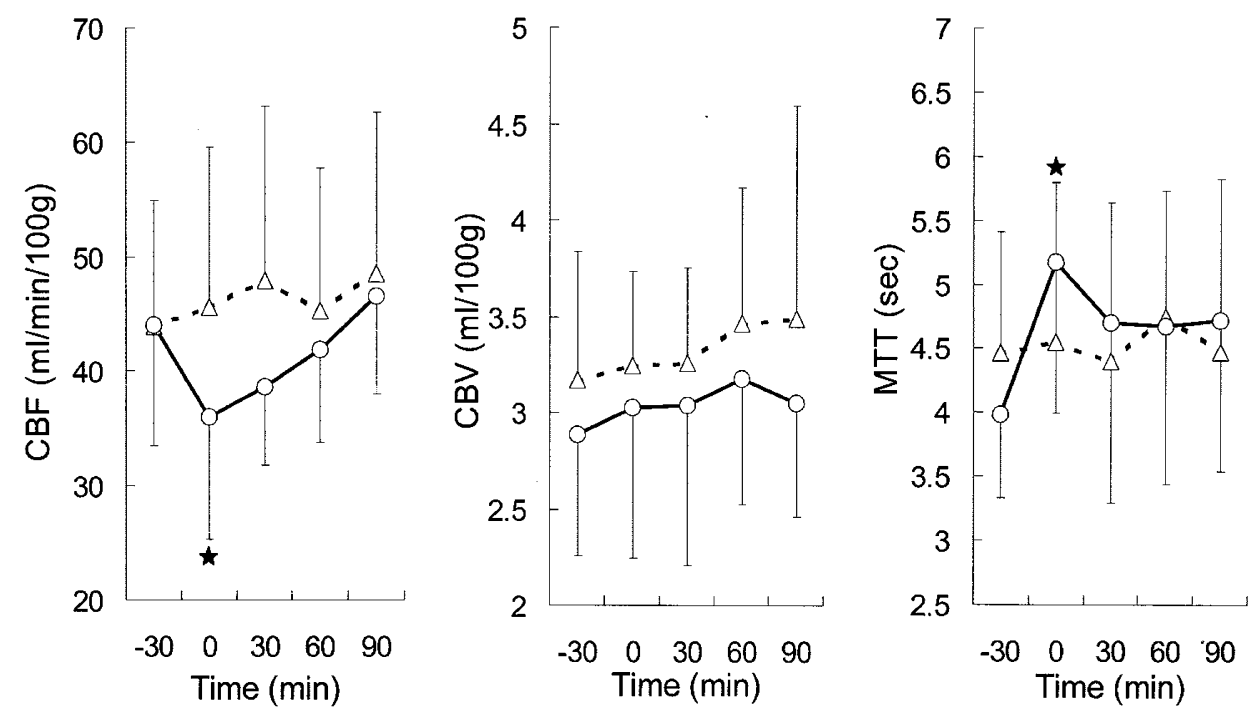

Figure 3. $\mathrm{CBF}, \mathrm{CBV}$, and MTT for control and indomethacin-treated piglets. Average CBF, CBV, and MTT in control (-- ---$)$ and indomethacin-treated $(-\bigcirc-)$ piglets. Significant differences from baseline are denoted by stars $(p<0.05)$.

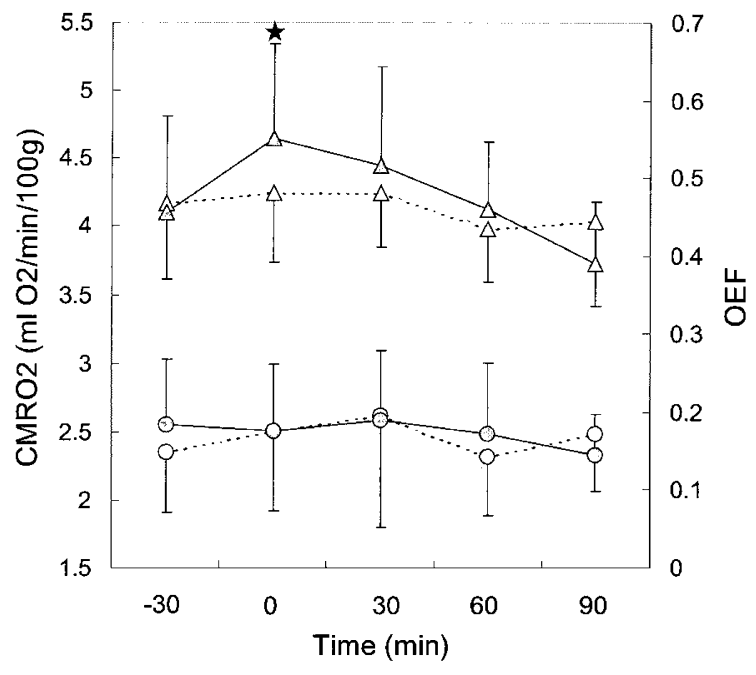

Figure 4. $\mathrm{CMRO}_{2}$ and $\mathrm{OEF}$ in control and indomethacin-treated piglets. Average $\mathrm{CMRO}_{2}$ and $\mathrm{OEF}$ in control (-- - ) and indomethacin-treated (-) piglets. $--\triangle--, \mathrm{OEF}$ in control piglets; $-\mathbf{\Delta}-, \mathrm{OEF}$ in indomethacin-treated piglets; - - $\mathrm{O}--, \mathrm{CMRO}_{2}$ in control piglets; - -, $\mathrm{CMRO}_{2}$ in indomethacin-treated piglets. Significant differences from baseline as denoted by stars ( $p$ $<0.05)$.

parameters presented in the current study are in agreement with those observed by Schumann et al. (32).

The accuracy of any $\mathrm{CMRO}_{2}$ measurement technique is dependent on the ability to measure accurately $\mathrm{CBF}, \mathrm{CaO}_{2}$, and $\mathrm{CvO}_{2}$. The NIRS CBF measurement technique used in the present study has been previously validated in the newborn piglet in our laboratory (18) and is unlikely to contribute greatly to error in $\mathrm{CMRO}_{2}$ measurement. $\mathrm{CaO}_{2}$ measurement requires accurate arterial $\mathrm{O}_{2}$ saturation data. In the present study, $\mathrm{SaO}_{2}$ was derived from $\mathrm{PaO}_{2}$ obtained from arterial blood samples using Kelman's conversion technique. This procedure involves the derivation of a "virtual" $\mathrm{pH}, \mathrm{PaCO}_{2}$, and temperature-dependent $\mathrm{O}_{2}$ dissociation curve, from which $\mathrm{SaO}_{2}$ then can be determined. It has been shown to be accurate provided accurate measures of $\mathrm{pH}, \mathrm{PaCO}_{2}, \mathrm{PaO}_{2}$, and temperature are available. Arterial blood gas samples were analyzed using standard techniques and therefore are unlikely to have generated undue error in our $\mathrm{SaO}_{2}$ measurement. By far the largest source of error in the presented $\mathrm{CMRO}_{2}$ values is that associated with the calculation of the arteriovenous $\mathrm{O}_{2}$ difference. This calculation combines our NIRS CBV and absolute $\mathrm{Hb}$ concentration measurements to determine the amount of $\mathrm{O}_{2}$ used in the region of the brain sampled with our NIRS technique. Although the concentration measurements themselves are relatively accurate, the necessary assumption that $70 \%$ of the cerebral circulation is in the venous compartment may lead to error in the arteriovenous $\mathrm{O}_{2}$ difference determination as the ratio of arterial, capillary, and venous compartments may not remain constant during disturbances in cerebral hemodynamics. The presented CBV data showed no significant changes from baseline throughout the study, and it is unlikely that the ratio of arterial, capillary, and venous compartments could change without concomitant changes in CBV. Furthermore, a recent study by Lee et al. (33) investigating the venous and arterial contributions of total blood volume in the adult rat brain showed that an increase in total CBV of $31 \%$ above baseline values elicited an increase in the arterial CBV fraction of only $9 \%$, from $20 \%$ to $29 \%$. A brief analysis shows that such a redistribution of the arterial, capillary, and venous compartments, with $30 \%$ in the arterial, $10 \%$ in the capillary, and $60 \%$ in the venous compartment, introduces an error of only \pm 0.5 $\mathrm{mL} \mathrm{O} \mathrm{O}_{2} \cdot \min ^{-1} \cdot 100 \mathrm{~g}^{-1}$ in $\mathrm{CMRO}_{2}$ values calculated using our technique. In addition, the observed increases in OEF immediately after indomethacin administration remain significant $(p<0.05)$ when calculations are performed using different CBV distribution ratios from $10 \%, 10 \%$, and $80 \%$ to $30 \%$, $10 \%$, and $60 \%$ for arterial, capillary, and venous compartments, respectively. However, the inability to accurately measure this ratio remains a concern when the NIRS technique is applied to situations in which CBV need not remain constant. Improved knowledge regarding the venous contribution of the 
NIRS signal may be possible using a technique described by Franceschini et al. (34) in which the amplitude of respirationinduced oscillations in NIRS-measured $\Delta \mathrm{Hb}$ and $\Delta \mathrm{HbO}_{2}$ concentrations is used to extract venous concentrations of $\Delta \mathrm{HbO}_{2}$ and $\Delta \mathrm{Hb}$. This approach will be investigated in our future work.

Because the NIRS CBF measurement technique has been previously validated and $\mathrm{CaO}_{2}$ was determined using standard techniques, the presented study in effect investigates the ability of NIRS to measure $\mathrm{CvO}_{2}$. Because $\mathrm{CaO}_{2}$ remained unchanged from baseline throughout the study, increases in OEF were the result of decreases in $\mathrm{CvO}_{2}$. A scenario in which $\mathrm{CMRO}_{2}$ is maintained through compensatory increases in OEF during indomethacin-induced reductions in $\mathrm{CBF}$, as was observed in the present study, provides an ideal means of investigating the ability of NIRS to measure changes in $\mathrm{CvO}_{2}$ by isolating the parameter of interest. Furthermore, the effect of indomethacin is transient, with both $\mathrm{CBF}$ and OEF returning to baseline values, providing a means of assessing the capacity of NIRS to accurately measure both increases and decreases in $\mathrm{CvO}_{2}$.

\section{CONCLUSION}

The results presented in the current study provide evidence of the possibility of bedside, noninvasive measurement of $\mathrm{CMRO}_{2}$ in the human infant. Whereas NIR light is able to penetrate biologic tissue relatively well, extracerebral structures such as bone and scalp detract from the amount of light interrogating cerebral tissue and thus introduce error in derived values. The technique described therefore is best suited for use in the newborn or preterm infant, in whom skull and scalp contributions are minimal. The ability to monitor changes in cerebral hemodynamics and metabolic rate, which are certainly present before clinically apparent manifestation of injury, at the bedside would allow for earlier diagnosis and possible prevention of cerebral injury in both the newborn and the preterm infant.

Acknowledgments. We thank R. Springett and D.T. Delpy for help with data collection and analysis. We also thank Photonics Research Ontario.

\section{REFERENCES}

1. Cotton RB, Stahlman MT, Kovar I, Catterton WZ 1978 Medical management of small preterm infants with symptomatic patent ductus arteriosus. J Pediatr 92:467-473

2. Pourcyrous M, Leffler CW, Bada HS, Korones SB, Busija DW 1994 Cerebral blood flow responses to indomethacin in awake newborn pigs. Pediatr Res 35:565-570

3. Pryds O, Greisen G, Johansen KH 1988 Indomethacin and cerebral blood flow in premature infants treated for patent ductus arteriosus. Eur J Pediatr 147:315-316

4. Patel J, Roberts I, Azzopardi D, Hamilton P, Edwards AD 2000 Randomized double-blind controlled trial comparing the effects of ibuprofen with indomethacin on cerebral hemodynamics in preterm infants with patent ductus arteriosus. Pediatr Res 47:36-42

5. Benders MJ, Dorrepaal CA, van de Bor M, van Bel F 1995 Acute effects of indomethacin on cerebral hemodynamics and oxygenation. Biol Neonate 68:91-99

6. van Bel F, Bartelds B, Teitel DF, Rudolph AM 1995 Effect of indomethacin on cerebral blood flow and oxygenation in the normal and ventilated fetal lamb. Pediatr Res 38:243-250
7. Coyle MG, Oh W, Petersson KH, Stonestreet BS 1995 Effects of indomethacin on brain blood flow, cerebral metabolism, and sagittal sinus prostanoids after hypoxia. Am J Physiol 269:H1450-H1459

8. Jobsis FF 1977 Non-invasive infrared monitoring of cerebral and myocardial oxygen sufficiency and circulatory parameters. Science 198:1264-1267

9. Brazy JE, Lewis DV 1986 Changes in cerebral blood volume and cytochrome aa3 during hypertensive peaks in preterm infants. Pediatrics 108:983-987

10. Ferrari M, De Marchis G, Nicola A, Agostino R, Nodari S, Bucci G 2001986 Cerebral blood volume and haemoglobin oxygen saturation monitoring in neonatal brain by near infrared spectroscopy. Adv Exp Med Biol 200:203-212

11. Chance B, Legallais V, Sorge J, Graham N 1975 A versatile time-sharing multichannel spectrophotometer, reflectometer, and fluorometer. Anal Biochem 66:498-514

12. Wyatt JS, Cope M, Delpy DT, Wray S, Reynolds EO 1986 Quantification of cerebral oxygenation and haemodynamics in sick newborn infants by near infrared spectrophotometry. Lancet 2:1063-1066

13. Cope M, Delpy DT 1988 System for long-term measurement of cerebral blood and tissue oxygenation on newborn infants by near infra-red transillumination. Med Biol Eng Comput 26:289-294

14. Yoxall CW, Weindling AM, Dawani NH, Peart I 1995 Measurement of cerebral venous oxyhemoglobin saturation in children by near-infrared spectroscopy and partial jugular venous occlusion. Pediatr Res 38:319-323

15. Reynolds O, Wyatt J, Azzopardi D, Delpy DT, Cady EB, Cope M, Wray S 1998 New non-invasive methods for assessing brain oxygenation and haemodynamics. Br Med Bull 44:1052-1075

16. Delpy DT, Cope M, van der Zee P, Arridge S, Wray S, Wyatt J 1988 Estimation of optical pathlength through tissue from direct time of flight measurement. Phys Med Biol 33:1433-1442

17. Matcher SJ, Cope M, Delpy DT 1994 Use of the water absorption spectrum to quantify tissue chromophore concentration changes in near-infrared spectroscopy. Phys Med Biol 39:177-196

18. Brown DW, Picot PA, Naeini JG, Springett R, Delpy DT, Lee TY 2002 Quantitative near infrared spectroscopy measurement of cerebral hemodynamics in newborn piglets. Pediatr Res 51:564-570

19. Bassingthwaigthe JB, Chinard FP, Crone C, Lassen NA, Perl W 1970 Definitions and terminology for indicator dilution methods. In: Crone C, Lassen NA (eds) Capillary Permeability. Munskgaard, Copenhagen, pp 665-669

20. Cenic A, Nabavi DG, Craen RA, Gelb AW, Lee TY 1999 Dynamic CT measurement of cerebral blood flow: a validation study. AJNR Am J Neuroradiol 20:63-73

21. Zierler KL 1965 Equations for measuring blood flow by external monitoring of radioisotopes. Circ Res 16:309-321

22. Meier PP, Zierler KL 1954 On the theory of the indicator-dilution method for measurement of blood flow and volume. J Appl Physiol 6:731-744

23. Kelman GR 1966 Digital computer subroutine for the conversion of oxygen tension into saturation. J Appl Physiol 21:1375-1376

24. Phelps ME, Huang SC, Hoffman EJ, Kuhl DE 1979 Validation of tomographic measurement of cerebral blood volume with C-11-labeled carboxyhemoglobin. J Nucl Med 20:328-334

25. Mintun MA, Raichle ME, Martin WR, Herscovitch P 1984 Brain oxygen utilization measured with $\mathrm{O}-15$ radiotracers and positron emission tomography. J Nucl Med 25:177-187

26. Meyer E 1991 15-O Studies with PET. In: Diksic M, Reba RC (eds) Radiopharmaceuticals and Brain Pathology Studied with PET and SPECT. CRC Press, Boca Raton, pp 165-197

27. Snedecor GW, Cochran WG 1967 Statistical Methods. The Iowa State University Press, Ames, pp 472-477

28. Iijima T, Aoyagi T, Iwao Y, Masuda J, Fuse M, Naoki K, Sankawa H 1997 Cardiac output and circulating blood volume analysis by pulse dye-densitometry. J Clin Monit 13:81-89

29. Springett R, Sakata Y, Delpy DT 2001 Precise measurement of cerebral blood flow in newborn piglets from the bolus passage of indocyanine green. Phys Med Biol 46:2209-2225

30. Ichord RN, Northington FJ, van Wylen D, Johnston MV, Kwon C, Traystman RJ 1999 Brain $\mathrm{O}_{2}$ consumption and glutamate release during hypoglycemic coma in piglets are temperature sensitive. Am J Physiol 276:H2053-H2062

31. Bauer R, Brust P, Walter B, Vorwieger G, Bergmann R, Fuchtner F, Steinbach J, el-Hallag E, Fritz A, Johannsen B, Zwiener U 2000 Relation between brain tissue pO2 and dopamine synthesis of basal ganglia - a 18FDOPA-PET study in newborn piglets. J Perinat Med 28:54-60

32. Schumann P, Touzani O, Young AR, Verard L, Morello R, MacKenzie ET 1996 Effects of indomethacin on cerebral blood flow and oxygen metabolism: a positron emission tomographic investigation in the anaesthetized baboon. Neurosci Lett 220:137-141

33. Lee SP, Duong TQ, Yang G, Iadecola C, Kim SG 2001 Relative changes of cerebral arterial and venous blood volumes during increased cerebral blood flow: implications for BOLD fMRI. Magn Reson Med 45:791-800

34. Franceschini MA, Boas DA, Zourabian A, Diamond SG, Nadgir S, Lin DW, Moore JB, Fantini S 2002 Near-infrared spiroximetry: noninvasive measurements of venous saturation in piglets and human subjects. J Appl Physiol 92:372-384 